\title{
Liberalismo, Corporativismo, Pluralismo e Neo-Corporativismo
}

\author{
Octavio Bueno Magano \\ Professor Titular de Direito do Trabalho \\ da Faculdade de Direito da Universidade \\ de São Paulo
}

\section{Introdução}

Não tencionamos aqui desenvolver conceitos em torno das ideologias acima enunciadas senão na medida necessária a explicar as relações entre elas e o Direito do Trabalho. As ideologias podem ser definidas como esquemas de pensamento e de ação em que a maioria das pessoas acredita, numa determinada fase da história ${ }^{1}$. Tendo presente esse conceito, vamos procurar demonstrar que a índole do Direito do Trabalho varia conforme o esquema ideológico, condicionante de seu desenvolvimento. $\mathrm{E}$ o faremos compartilhando da opinião de Palomeque, no sentido de que o Direito do Trabalho não surge de forma espontânea, "de um impulso generoso e desprendido dos núcleos diretores da sociedade", sendo, ao contrário, fruto de ideologias ${ }^{2}$.

\section{Liberalismo}

A característica fundamental do liberalismo se traduz na crença da liberdade individual. O liberalismo é uma sociedade de participação limitada ${ }^{3}$. De acordo com essa ideologia, o homem sai do estado natural alienando apenas parte de sua liberdade e conservando, portanto, direitos fundamentais. Decorre daí a exigência de que o Estado seja abstencionista, limitando a sua ação ao mínimo indispensável à preservação da coesão social.

1. Bagolini, Luigi, Filosofia del Lavoro, Milano, Giuffrè, 1977, págs. 29/31. Vide também Palomeque, que assim conceitua a ideologia: "sistema de representaciones, conceptuales, valorativas e incluso intuitivas, de una clase, estrato o grupo." (Palomeque, M. Carlos, Derecho del Trabajo e Ideologia, Madrid, Akal, 1980, pág. 73).

2. Palomeque, ob. cit., pág. 73.

3. Prélot, Marcel, Histoire des Idées Politiques, Paris, Dalloz, 1966, pág. 381. 
Para que o Estado não tenha extravazamentos, o seu poder deve ser dividido, nos termos da máxima de Montesquieu: "le pouvoir arrête le pouvoir".

A preservação da liberdade individual exige, por outro lado, a proibição da existência de corpos intermediários entre o Estado e os indivíduos ${ }^{4}$.

Por último, é preciso considerar a dimensão econômica do liberalismo, consoante a qual cada indivíduo, buscando o seu próprio interesse, proporciona a satisfação do interesse geral.

No quadro acima descrito, não há lugar para o desenvolvimento do Direito do Trabalho, por duas razões principais. Primeiro, porque essa disciplina, para se constituir, exige um mínimo de atividade estatal continuada, seja organizando sistema normativo destinado a proteger o trabalhador, como se deu nos países de tradição romanogermânica, seja estabelecendo estrutura capaz de proteger as organizações por eles constituídas, como ocorreu nos países da "Common Law". Segundo, porque o Direito do Trabalho supõe a atuação de corpos intermediários, a saber, os sindicatos, cuja existência não se compatibiliza com os padrões do liberalismo.

Não obstante, força é reconhecer que os primeiros marcos do Direito do Trabalho foram implantados durante o liberalismo. Surgiram, com efeito, no correr do século XIX, as primeiras leis de proteção ao menor, leis de fiscalização do trabalho, leis permissivas da atividade sindical. Contudo, a legislação editada nesse período distingue-se da que lhe é superveniente, posterior ao término da Primeira Grande Guerra, nisto que as últimas são tuitivas, abundantes e sistemáticas, enquanto as primeiras se mostram neutras, escassas e casuais.

A neutralidade apontada baseia-se na concepção de que todos os indivíduos são iguais perante a lei, o que resultava afinal numa grande inferioridade do trabalhador, em virtude de reduzido poder de barganha, decorrente de sua debilidade econômica.

A escassez referida constitui mero corolário de ser abstencionista o Estado liberal, do que resultava que só excepcionalmente intervinha na ordem econômica e social.

A casualidade de que se trata explica-se também pela natureza não intervencionista do Estado liberal, o que o fazia editar leis trabalhistas somente quando premido por circunstâncias especiais. Assim, no Brasil, a primeira lei sobre prestação de serviços, de 13 de setembro de 1830, está ligada à convenção que o Brasil celebrara com a Inglaterra, em 23 de novembro de 1826, e na qual se estipulava que, a partir de três anos após as ratificações do ajuste, o tráfico de escravos

4. Rousseau, J. J., Du Contrat Social, Paris, Egloff, 1946, pág. 73. Vide também Sieyes, Emmanuel, Q'est-ce que le Tiers état? Genève, Droz, 1970, pág. 206. 
passaria a ser considerado pirataria. A lei $\mathrm{n}^{\circ} 108$, de 11 de outubro de 1837, teve, a seu turno, em vista a disciplina dos contratos de prestação de serviços com estrangeiros pertencentes às primeiras correntes migratórias destinadas ao país. O descreto $n^{\circ} 2.827$, de 15 de março de 1879, relacionava-se com o mesmo objetivo, mas numa fase em que as imigrações haviam tomado maior realce.

\section{Corporativismo}

A idéia básica do corporativismo é a da organização das forças econômicas em torno do Estado, com o fito de promover o interesse nacional e contando com o poder de impor regras a todos os seus membros ${ }^{5}$.

Na Itália, onde o corporativismo teve bem-sucedida realização o Estado erigiu-se num fim ético para o qual deveriam convergir as ações dos individuos e dos grupos ${ }^{6}$. De acordo com isso, dispunha o item I da "Carta del Lavoro": "A Nação italiana constitui organismo com fim, vida e meios de ação superiores, não só em força mas também em duração, aos indivíduos e grupos que a compõem. É uma unidade moral, política e econômica, que se realiza integralmente no Estado Facista." As forças econômicas organizam-se sob a forma de corporações ? . Nessa conformidade, preceituava o item VI da "Carta del Lavoro": "As corporações constituem a organização unitária das forças da produção representando integralmente o interesse delas." O sindicato, como elemento componente das corporações, tornou-se órgão do Estado ${ }^{8}$ e representante da categoria profissional, em nome da qual podia celebrar contratos coletivos de trabalho, com eficácia "erga omnes". A categoria profissional erigiu-se em critério de organização dos sindicatos, figurando como verdadeiro e novo sujeito de direito ${ }^{\circ}$.

Manifesta é a contraposição do corporativismo ao liberalismo. Primeiro, porque se apresenta como organização dos grupos econômicos e profissionais, enquanto o liberalismo pressupõe que o bem comum se realize automaticamente, pela atuação dos indivíduos, perseguindo os próprios interesses. Segundo, porque implica função coordenadora e diretiva do Estado ${ }^{10}$, ao contrário do liberalismo, que o quer abstencionista. Terceiro, porque atribui aos grupos profissionais o poder de impor regras aos membros respectivos, ao passo que o liberalismo nem sequer admite a existência deles.

5. Manoilesco, Mihail, Le Siècle du Corporativisme, Paris, Félix Alcan, 1936, pág. 167. pág. 43.

6. Del Vecchio, Gustavo, I Principii della Carta del Lavoro, Padova, Cedam, 1937,

7. Idem, pág. 55 .

8. Carta del Lavoro, item VI.

9. Barassi, Lodovico, Diritto Sindacale e Corporativo, Milano, Giuffrè, 1938, pág. 47.

10. Idem, pág. 10. 
A concepção corporativista transplantou-se para a Carta Constitucional brasileira, de 10 de novembro de 1937, de acordo com as seguintes linhas fundamentais: a) organização corporativa da economia, o que implicou a constituição de órgãos representativos do capital e do trabalho, em função piramidal, sob a supervisão do Estado ${ }^{11}$; b) delegação de poderes aos mesmos órgãos para se tornarem representantes de categorias profissionais, celebrando em nome delas contratos coletivos de trabalho ${ }^{12}$; c) criação do conceito de categoria, isto é, grupo profissional e econômico organizado conformemente aos desígnios políticos do Estado ${ }^{13}$; d) supressão dos conflitos sociais, notadamente das greves ${ }^{14}$; e) instituição da Justiça do Trabalho para os dirimir ${ }^{15}$.

Essas linhas básicas da Constituição ramificaram-se abundantemente, por obra da legislação ordinária. Resultou daí aparatosa organização sindical com as seguintes características: a) implantação do princípio da unidade sindical, com previsão de constituição de um único sindicato representativo de categoria profissional e econômica, numa determinada base territorial (geralmente o Município); b) integração do sindicato num sistema de relacionamento hierárquico com Federações e Confederações, constituídas respectivamente por categorias e ramos de atividade econômica; c) sujeição das entidades sindicais ao Ministério do Trabalho, através dos seguintes mecanismos: registro, fiscalização, intervenção, destituição de diretores, expulsão de associados, extinção; d) predeterminação das funções a serem exercidas pelos sindicatos.

A primeira das funções atribuídas ao sindicato foi a de representação da categoria profissional, com poderes de celebrar contratos coletivos de trabalho, que poderiam ser estendidos a todos os membros da respectiva categoria profissional; a segunda das atribuições conferidas ao sindicato foi a econômica, consistente na possibilidade de cobrar coercitivamente contribuição sindical de todos os membros da respectiva categoria profissional. A terceira das funções outorgadas ao sindicato foi a assistencial, cuja importância se realçava através da vinculação a ela da maior parte da receita obtida com a arrecadação da contribuição sindical compulsória.

Além da organização sindical, com as características acima mencionadas, montou-se também, em conformidade com a Constituição de 1937, outra aparatosa organização, destinada a dirimir os conflitos trabalhistas, a que se denominou Justiça do Trabalho.

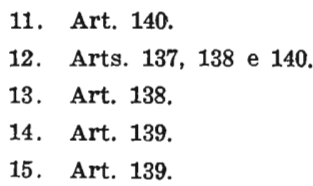


Se os conflitos sociais, que se traduziam em vias de fato, consideravam-se recursos anti-sociais ${ }^{16}$, nos termos da referida Constituição, tornava-se de rigor a canalização deles para o terreno das soluções impostas por órgãos estatais.

Para o efeito indicado, instituiu-se a Justiça do Trabalho, com competência para julgar tanto dissídios coletivos como individuais. Inicialmente, deram-lhe feição administrativa. Com o advento da Constituição de 1946, tornou-se órgão do Poder Judiciário.

As suas características atuais que pouco diferem daquelas existentes ao tempo de sua implantação, são resumidamente as seguintes: a) trata-se de organização paritária, o que significa que cada um de seus órgãos possui membros alheios aos interesses classistas e também representantes de empregados e de empregadores; b) a sua atuação se dá em três níveis: o das Juntas de Conciliação e Julgamento, com jurisdição local; o dos Tribunais Regionais do Trabalho, com jurisdição geralmente correspondente ao território estadual; e o Tribunal Superior do Trabalho, com jurisdição em todo o território nacional; c) no âmbito de sua competência, inserem-se tanto os dissídios individuais quanto os dissídios coletivos, incluindo-se entre os últimos os econômicos e os jurídicos.

Como se depreende do exposto, no esquema do Corporativismo, não há quase espaço para a atuação dos mecanismos de autocomposição, como a negociação coletiva, a convenção coletiva, a arbitragem voluntária e a greve, prevalecendo, ao contrário, de forma hegemônica, os mecanismos de tutela.

\section{Pluralismo}

O pluralismo significa a livre atuação dos indivíduos e dos grupos componentes da sociedade civil, na persecução dos interesses que lhes são próprias. Numa sintese mais apertada, poderíamos dizer que o pluralismo corresponde à existência, no seio da sociedade civil, de centros autônomos de produção jurídica, entendendo-se que as normas deles oriundas possuem a mesma natureza das emanadas pelo Estado, com a diferença de que as do último são dotadas de mais intensa positividade ${ }^{17}$. O aspecto de maior relevância do pluralismo é pois a negação da exclusividade normativa do Estado.

Coloca-se assim o pluralismo em contraposição frontal ao monismo jurídico, concepção segundo a qual goza o Estado do monopólio

16. Interpretando a concepção então vigente eis como se referia à greve Theotônio Monteiro de Barros Filho: "Phenomeno da vida collectiva, já não é, entretanto, havida como forma normal de manifestação de anceios legitimos. A tendência é para emprestar-lhe um caracter mórbido. Forma de lucta, num momento em que a grande preocupação de juristas e sociólogos, ao lado do Estado, é a de fixar processos harmônicos e pacíicos de compor um equilíbrio estavel entre as formas do Capital e do Trabalho, ella passa a ser tida como nociva e anti-social, passivel de repressão"

17. Del Vecchio, Giorgio, Leçons de Philosophie du Droit, Paris, Sirey, 1936, pág. 297 
da produção jurídica. O monismo, como se sabe, tornou-se a concepção dominante a partir da Revolução Francesa e está implícito no movimento desencadeado no início do século XIX em prol da codificação ${ }^{18}$. Bem o externou Von Lhering ao dizer: "O Estado é a única fonte do Direito. A autonomia exercida de fato por muitas associações ao lado do Estado, não contradiz esta asserção. Essa autonomia encontra a sua base jurídica numa concessão expressa ou na tolerância tácita do Estado. Não existe por si mesma, deriva do Estado" ${ }^{19}$.

O formidável crescimento dos grupos profissionais nos países industrializados, ocorrido no curso do século $X X$, e a sua crescente influência na solução dos problemas políticos parecem desmentir a tese monista. Mostram-se, assim, mais condizentes, com a realidade de nossa época, estas palavras de Del Vecchio: "A dependência de todos os órgãos sociais à organização jurídica do Estado se resolve freqüentemente numa simples "fictio juris", já que, na realidade, encontram-se organismos sociais que vivem "jure proprio", não se vinculando ao Estado senão por liames externos, ou através de relações acentuadamente genéricas, que não afetam a sua estrutura e que não destroem consequientemente a autonomia de sua organização intrínseca" ${ }^{20}$.

Sendo a sociedade civil composta de vários centros de poder, cada um deles desenvolve o seu sistema normativo, ressalvada a predominância do sistema estatal. Vale dizer, em outras palavras, que os grupos gozam de autonomia, enquanto o Estado detém a soberania. Tal autonomia se define como poder de auto-regrar os próprios interesses ${ }^{21}$, o qual, no que concerne aos grupos profissionais e econômicos, se exterioriza na celebração de convenções coletivas de trabalho. A convenção coletiva se concebe, assim, não como delegação de poder estatal, mas como autêntica manifestação de poder grupal, o qual não deve sofrer ingerências estatais.

Do ponto de vista político, o que se realça é a existência de um sistema em que as decisões provém da interação e da competição de uma multiplicidade de grupos representando interesses sociais diversos, cabendo ao Estado a função de mero árbitro na solução dos interesses conflitantes. $\bar{A}$ luz do pluralismo, a sociedade civil se concebe como um conjunto de entes individuais e coletivos, em permanente atividade, na busca dos interesses que lhes são próprios, e o Estado como o ente ao qual incumbe harmonizar os conflitos surgidos da mesma atividade ${ }^{22}$. Há de se acentuar ainda que a quantidade de grupos participantes das decisões adotadas, no âmbito de cada siste-

18. Fassò, Guido, Histoire de la Philosophie du Droit, Paris, L.G.D.J., 1974, pág. 2.

19. Von Lhering, Rudolf, A Evolução do Direito, Lisboa, José Bastos, s.d.p., págs. $220 / 221$.

20. Del Vecchio, ob. cit., Leçons..., pág. 294.

21. Santi Romano, Fragmentos de un Diccionario Juridico, Buenos Aires, Ediciones Juridiques Europa-América, 1964, pág. 37. 
ma, é potencialmente ilimitada, o que quer dizer que os grupos são tantos quantos sejam os interesses justificativos de uma organização. $\mathrm{E}$ preciso registrar, finalmente, que, do ponto de vista negativo, o pluralismo significa a valorização do grupo profissional e econômico como instrumento vertical da limitação do poder estatal ${ }^{23}$.

O pluralismo pode ser tido como nova versão do liberalismo, dele se assemelhando pela liberdade outorgada aos protagonistas sociais, na realização de seus interesses e, ainda, pelo tipo de vinculação do Estado aos programas sociais e econômicos, geralmente, de caráter indutivo. Dele se distingue porque não antagoniza os corpos intermediários, reconhecendo-lhes, ao contrário, a autonomia e, ainda, porque não se alheia dos problemas sociais e econômicos.

O pluralismo, com as apontadas feições, pode ser também denominado de neo-liberalismo e tem sido a ideologia dominante no mundo ocidental, desde o término da Segunda Grande Guerra Mundial. As constituições que o acolhem dão prioridade aos mecanismos de autocomposição para a solução dos problemas sociais. Vale dizer que a negociação coletiva, a convenção coletiva, a greve, a conciliação, a mediação e a arbitragem voluntária se tornam as formas dominantes de exteriorização das relações trabalhistas.

No Brasil, a transposição do corporativismo para o pluralismo democrático nunca chegou a se consumar plenamente. Se, por um lado, a Constituição de 1946 fazia repousar a ordem econômica no princípio da liberdade de iniciativa ${ }^{24}$, mantinha, por outro lado, a regra de que os sindicatos exercem funções delegadas do poder público ${ }^{25}$ o que é incompatível com a idéia de autonomia sindical. A continuidade da tendência corporativa se revela quiçá, de modo mais acentuado na manutenção da Justiça do Trabalho, como organismo de tutela estatal destinado a dar solução aos conflitos trabalhistas.

A nível de legislação ordinária, pode-se dizer que ficaram intatas as estruturas corporativas concernentes aos sindicatos e à Justiça do Trabalho. Isso quer dizer, em outras palavras, que as relações trabalhistas, a despeito do advento da Constituição de 1946, continuaram a ser regidas através de mecanismos de tutela estatal e não por mecanismos de autocomposição e autodefesa, como é mais próprio dos sistemas democrático-pluralistas.

Nos Estados Unidos, por exemplo, o Governo intervém na esfera das relações industriais apenas para garantir aos trabalhadores o direito de se organizarem em sindicatos e de, através destes, nego-

22. Loewentein, Karl, Political Power and the Governmental Process, Chicago, The University of Chicago Press, 1965, pág. 344.

23. Idem, pág. 344 .

24. Art. 145 .

25. Art. 159 . 
ciarem coletivamente ou usarem de meios de pressão para o sucesso de suas reinvidicações ${ }^{26}$. Abstém-se, porém, de se imiscuir na determinação do conteúdo das relações de emprego, ou de outorgar a órgão administrativo ou judiciário o poder de fazê-lo ${ }^{27}$.

Ressalvadas as peculiaridades de cada país, parece certo que o referido modelo teve influência preponderante, na conformação dos sistemas de relações industriais dos países da Europa Ocidental, após o término da Segunda Grande Guerra. O caso da Itália é bem ilustrativo. Como assinalam Carinci, Tamajo, Tosi e Treu, " .o sistema italiano de relações industriais, após a Segunda Grande Guerra, desenvolveu-se fora de qualquer esquema legislativo, não só no que concerne aos protagonistas do sistema - sindicatos e organizações empresariais - mas igualmente no que respeita a outros dois institutos fundamentais, o contrato coletivo de trabalho e o conflito" ${ }^{28}$.

No Brasil, como já assinalamos, não foi isso o que se deu. A despeito de havermos adotado, em 1946, uma constituição democrática, as nossas relações industriais continuaram a ser regidas por mecanismos de tutela, de ressaibo claramente corporativista.

Para que se inverta essa situação, é mister a total revisão da legislação ordinária, feita de acordo com os critérios abaixo-indicados.

Cumpre, antes de mais nada, abandonar o mito de que a categoria constitui pressuposto lógico da existência do sindicato. Isso só se admite à luz da concepção corporativista. Sob o prisma do pluralismo, os grupos profissionais e econômicos ganham identidade através de um ato de autonomia negocial, que transforma um amorfo sociológico em uma organização ${ }^{29}$. Vale dizer que a categoria não constitui antecedente necessário do sindicato, que, assim, pode abranger todos os trabalhadores de uma categoria, ou os de uma cidade, ou apenas os trabalhadores de uma empresa. Tudo depende da vontade dos participantes do grupo e da força que tiverem para se organizarem.

Esse é o critério de organização seguido em todos os países em que prevalece o modelo pluralista, como é o caso dos Estados Unidos, da Itália e da Espanha.

O abandono da idéia de categoria, como antecedente necessário do sindicato, implica igualmente o desaparecimento do conceito de território, como espaço geográfico em que aquela se situa. Sob a rubrica do pluralismo, o sindicato pode atuar no espaço geográfico de sua escolha, seja este o correspondente aos limites de uma empresa,

26. Cox, Arquibald, Law and the National Labor Policy, Los Angeles, University of California, 1960, pág. 2.

27. Idem, pág. 11.

28. Carinci, F.; De Luca Tamajo, R.; Tosi, P.; Treu, T. Diritto del Lavoro, Torino,UTET, 1983, pág. 27.

29. Grugni, Gino, Diritto Sindacale, Bari, Cacucci, 1980, pág. 72. 
de uma cidade, de um município, de um Estado ou aos do território nacional.

Outro traço da organização atual incompatível com o modelo pluralista é o que se traduz na estreita vinculação entre governo e sindicato e que autoriza o primeiro a intervir na administração do último, destituindo diretores até mesmo dissolvendo o próprio sindicato. Ao contrário disto, o modelo pluralista supõe total desvinculação entre o Estado e o sindicato. Em alguns países, como é o caso da Inglaterra e da Itália, até mesmo o registro do sindicato se reputa incompativel com a liberdade sindical ínsita ao modelo pluralista.

$\mathrm{O}$ terceiro traço da organização atual incompativel com o modelo pluralista é o referente à contribuição sindical compulsória. A compulsoriedade da exigência briga com a liberdade sindical inerente ao pluralismo. Por outro lado, deforma a própria organização sindical, porque lhe dá força econômica quase sempre desacompanhada de representatividade. Por último, é preciso assinalar que a contribuição sindical compulsória, implicando captação de meios econômicos por imposição estatal, coloca inevitavelmente o sindicato sob a dependência do Estado, o que é claramente contrário à idéia de liberdade sindical própria do modelo pluralista.

A incompatibilidade da legislação brasileira com o modelo pluralista se patenteia não apenas no que concerne à organização sindical senão também no que respeita à própria existência da Justiça do Trabalho. Como já se assinalou anteriormente, esta foi criada sob a égide do corporativismo, como mero sucedâneo da proibição que este impunha aos conflitos trabalhistas, que pudessem se traduzir em vias de fato, notadamente a greve. A Justiça do Trabalho constitui, pois, mecanismo de tutela engendrado pelo corporativismo e que se mostra incompatível com os mecanismos de autocomposição de conflitos, próprios do modelo pluralista.

\section{Neocorporativismo}

O neocorporativismo possui basicamente as mesmas caracteristicas do corporativismo, despojado, porém, da carga ideológica facista, que lhe era própria. Distingue-se, ademais, do último por não ser compulsório e sim voluntário.

O neocorporativismo parte assim da premissa de que a harmonia das classes sociais é essencial ao funcionamento e à estabilidade da sociedade civil. Nutre-se da idéia de que tal harmonia só pode ser assegurada, se os vários grupos componentes da sociedade global, notadamente os profissionais e os econômicos, reconhecerem a existência de direitos e deveres recíprocos. Desdobra-se no conceito de que os mesmos grupos devem gozar de influência nas decisões políticas e ao mesmo tempo assumir responsabilidade quanto à atuação de seus membros, controlando-a, a fim de que não se afaste dos objetivos de rele- 
vância social previamente estabelecidos. Sob o rótulo de neocorporativismo, intenta-se, em suma, identificar estrutura política na qual as decisões estatais se baseiam na participação dos grupos profissionais e econômicos mais representativos, ou melhor, estrutura na qual os protagonistas são a um tempo o Estado e os grupos profissionais e econômicos mais representativos.

Em conformidade com as apontadas características, o neocorporativismo pode ser definido como modelo institucionalizado de formação de decisões políticas, no qual as grandes organizações de interesses colaboram entre elas e com a autoridade pública, não só na realização dos mesmos interesses mas também na realização dos objetivos da comunidade ${ }^{30}$.

As feições do neocorporativismo melhor se realçam assinalando-se as diferenças com o corporativismo e com o pluralismo.

Do corporativismo diferencia-se basicamente nisso que o último é coercitivo enquanto o primeiro é voluntário. As demais diferenças constituem desdobramentos desta. Assim, pressupõe o neocorporativismo que a estrutura sindical não fique na dependência de diretrizes estatais, nem tampouco vinculada à realização de objetivos estabelecidos unilateralmente pelo Estado, mas, ao contrário, continue livre, de acordo com os moldes pluralistas, matizados apenas pela tendência no sentido de maior centralização ${ }^{31}$. As negociações entre as partes não ficam na dependência do "placet" governamental; devem ser, porém, desenvolvidas dentro dos limites estabelecidos no pacto social celelebrado entre o Estado e as entidades mais representativas de trabalhadores e empregadores. Os conflitos coletivos, que se traduzem em vias de fato, não ficam proibidos nem se estabelecem órgãos para julgá-los, de forma compulsória, o que não exclui, todavia, a expectativa de autodisciplina das partes, no que concerne ao seu desencadeamento.

O neocorporativismo implica cooperação tripolar, na qual os protagonistas são o Estado e as entidades mais representativas de empregados e de empregadores, mas isso sem prejuízo da preservação de instituições democráticas e do reconhecimento da posição conflitiva entre o capital e o trabalho. Por isso mesmo, é comum que seja também denominado de pluralismo organizado.

Do modelo pluralista distingue-se o neocorporativismo, pelo reconhecimento implícito, no último modelo, da necessidade de cooperação entre os parceiros sociais, inclusive o Estado, na consecução dos objetivos relevantes da comunidade. A idéia dominante deixa de ser, portanto, a de uma sociedade conflitiva, em que cada grupo persegue os próprios interesses e na qual o Estado se limita a manter o equilíbrio entre interesses contrapostos.

30. Mafaffi, Marco, La Società Neo-Corporativa, Bologna, Mulino, 1981, pág. 22.

31. Idem, pág. 33 . 
O instrumento mais significativo de atuação do neocorporativismo é o pacto social, através do qual os grupos profissionais e econômicos, em colaboração com o Estado, delineiam soluções para os problemas econômico-sociais ${ }^{32}$. A heterogeneidade e a amplitude das matérias contidas nesses pactos têm dificultado a determinação de sua natureza jurídica. Nada obsta, porém, a indicação desta por aproximação. Numa primeira tentativa de aproximação, pode-se dizer que os pactos não constituem imposições governamentais, melhor caracterizando-se como manifestações de autonomia dos grupos profissionais e econômicos, que deles participam. Isso bem se realça quando os mesmos pactos se celebram sem participação governamental, como tem sucedido na Espanha. Mas, mesmo quando se dá o contrário, como ocorreu no país citado com o Acordo Nacional sobre Emprego, de 1982 e, na Itália, com o Acordo sobre custo do trabalho, de 22 de janeiro de 1983, a apontada característica não se desmente, podendo-se falar apenas numa limitação da questinada autonomia ${ }^{33}$, a qual, como se sabe, já corresponde, por si, à idéia de poder limitado. Há de se registrar, em seguida, que os pactos em foco não se identificam com as convenções coletivas de trabalho, conceituadas como instrumentos de determinação do conteúdo de contratos individuais de trabalho. Tal identificação não é possível porque os pactos em causa não têm em vista o conteúdo de tais contratos e sim o das convenções coletivas do trabalho ${ }^{34}$. Por essa razão, talvez melhor se caracterizem como marcos de estrutura das convenções coletivas ${ }^{35}$.

O conteudo dos pactos em causa é, como já se disse, amplo e heterogêneo. Contudo, isso não impede de se indicarem os tópicos de maior importância geralmente neles inseridos, a saber: a) objetivo de combate à inflação e ao desemprego; b) medidas de ordem econômica a serem adotadas pelos pactuantes, para colimarem o referido objetivo; c) fixação de diretrizes a serem obedecidas na celebração de convenções coletivas; d) diminuição da conflitividade entre os parceiros sociais, nos diversos níveis de sua atuação; e) racionalização do processo de negociação coletiva, com o fito de evitar a sua excessiva atomização e a duplicação de linhas de negociação.

32. Treu, Tizino, L'intervento del sindacato nella politica economica, "in" Giornale di Diritto del Lavoro e di Relazioni industriali, Milano, ne 17, anno V, 1983, pág. 81.

33. "Prevale, dunque, il contratto, ancorché si tratti di un contratto colletivo mediato, neỉ termini e con il valore di cui si dirá, dal potere pubblico; prevale, cioè, un indirizzo che non confida in sokuzioni eternome dei conflitti sociali, ma si impernia sul ruolo dell'autonomia collettiva, sistenuta dai publici poteri. Insomma, una soluzione neocontrattuale palesa rinnovato vigore, la cui effettiva portata sarà dimostrata nell'attuazione dell'accordo." Pehone, Gian, Carlo L'Accordo Sul Costa del Lavoro, Problemi e Prospettive, "in". Il Diritto del Lavoro, 1983, Fasc. 2, Parte I, Roma, Fondazione Diritto del Lavoro, 1983, pág. 93.

34. Alonso Garcia, Manoel, La Naturaleza del Acuerdo Marco Interconfederal, "in" Comentarios al Acuerdo Marco Interconfederal sobre Negociación Colectiva, Madrid, Instituto de Estudios Sociales, 1980, págs. 32/33.

35. Viđal Caruana, Negociación Colectiva 83, Madrid, APD, 1983; pág. 5. 
Os pactos sociais, com as características acima apontadas, tendo voga cada vez maior, nos países da Europa Ocidental, se não traduzem adesão dos mesmos países ao modelo neocorporativista, indicam, sem dúvida, clara tendência nesse sentido. A propensão em causa já se trasladou para a América Latina, como se depreende da celebração do Pacto de Solidariedade Nacional, recentemente celebrado no México.

\section{Conclusões}

Não é facil indicar a ideologia ou as ideologias destinadas a exercer maior influência na elaboração do Direito do Trabalho. Contudo, algumas podem ser tidas como exauridas, quanto ao poder de gerar proselitismo: é o caso do liberalismo e do corporativismo. Assim, é de se prever que a evolução do Direito do Trabalho, no mundo ocidental, deverá ocorrer em conformidade com estas duas linhas de pensamento: a do pluralismo e a do neocorporativismo.

Qual das apontadas linhas de evolução será mais conveniente para a América Latina?

A América Latina possui longa tradição de intervencionismo estatal não só na disciplina das relações individuais de trabalho como também na solução dos conflitos respectivos e na limitação das manifestações coletivas ${ }^{36}$. Contudo, há sinais de uma tendência no sentido de mais acentuada autonomia dos protagonistas sociais, o que se pode atribuir aos seguintes fatores: a) envelhecimento dos códigos de trabalho que não se mostram mais aptos a solucionar todos os problemas trabalhistas da sociedade contemporânea; b) aumento do número das grandes empresas, em que é mais marcante a inclinação a negociar coletivamente; c) advento de nova geração de gerentes de relações humanas, mais propensos aos mecanismos de autocomposição ${ }^{37}$. Força é reconhecer, porém, que o mecanismo intervencionista continua dominante ${ }^{38}$.

Em termos de ideologia, desejável seria que o primeiro mecanismo suplantasse o último, por ser mais consentâneo com o modelo democrático-pluralista. Contudo, na prática, grandes seriam os riscos de que o mesmo modelo se convertesse numa farsa, na qual os atores, sob a aparência de servirem interesses próprios, estivessem, na verdade, exteriorizando interesses de grupos dominantes. $O$ que se quer dizer, em outras palavras, é que a prática do modelo pluralista exige a atuação de parceiros sociais preparados, com equilíbrio de forças. Faz-se mister, portanto, para que este funcione adequadamente, o fortalecimento das organizações sindicais e a melhor formação educacional de seus líderes.

36. C6rdova, Efrén, Las Relaciones Colectivas de Trabajo en America-Latina, Ginebra, OIT, 1981, pág. 1.

37. Idem, pág. 7 .

38. Ibidem, pág. 13. 
Enquanto as apontadas exigências não se colimarem, o ủnico modelo viável para a América Latina é o dualista, ou seja, uma mistura de autonomia coletiva e de intervencionismo estatal, com a ressalva ideológica de que o comportamento autônomo deve ser o fator dinâmico, a.fim de que, ao longo do tempo, possa suplantar ou outro fator. O dinamismo em causa exige, porém, o robustecimento institucional dos mecanismos de autocomposição, nos moldes do decreto $n^{\circ} 88.984$, baixado pelo Governo brasileiro, em 10 de novembro de 1983 e cujo escopo é exatamente o de estimular e proteger os mecanismos de negociação coletiva, de mediação e de arbitragem.

Há, portanto, probabilidades grandes de que o modelo dominante de relações industriais, na América Latina, venha ser o de neocorporativismo, adaptado naturalmente às peculiaridades de nossa região. 